\title{
Sumoylation of hypoxia inducible factor-1 $\alpha$ and its significance in cancer
}

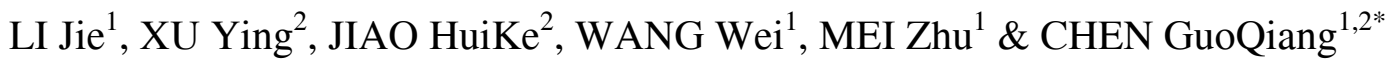 \\ ${ }^{1}$ Department of Pathophysiology, Chemical Biology Division of Shanghai Universities E-Institutes, Key Laboratory of Cell Differentiation and \\ Apoptosis of Ministry of Education, Shanghai Jiao Tong University School of Medicine, Shanghai 200025, China; \\ ${ }^{2}$ Institute of Health Sciences, Shanghai Institutes for Biological Sciences of Chinese Academy of Sciences \& Shanghai Jiao Tong University \\ School of Medicine, Shanghai 200025, China
}

Received March 22, 2014; accepted April 15, 2014; published online June 10, 2014

\begin{abstract}
Hypoxia-inducible factor-1 (HIF-1) is a key heterodimeric transcription factor for the cellular adaptive response to hypoxia, a common feature of the microenvironment in solid tumors. The transcriptional activity, protein stabilization, protein-protein interactions and cellular localization of HIF-1 $\alpha$, an oxygen-sensitive subunit of HIF-1, are mainly modulated by various post-translational modifications. Recently, we reported that polycomb chromobox $4(\mathrm{Cbx} 4)$ governs the transcriptional activity of HIF- $1 \alpha$ by enhancing its sumoylation at K391 and K477, through which Cbx4 potentiates angiogenesis of hepatocellular carcinoma. This review summarizes the current knowledge of HIF-1 $\alpha$ sumoylation and its roles in the pathogenesis of cancer.
\end{abstract}

HIF-1 $\alpha$, sumoylation, cancer

Citation: Li J, Xu Y, Jiao HK, Wang W, Mei Z, Chen GQ. Sumoylation of hypoxia inducible factor-1 $\alpha$ and its significance in cancer. Sci China Life Sci, 2014, 57: 657-664, doi: 10.1007/s11427-014-4685-3

Hypoxia, a common characteristic of the microenvironment for cancer cells, promotes changes in metabolism (e.g., changes from oxidative phosphorylation to glycolysis), and the progression and metastasis of solid tumors [1-3]. Transcription factors known as hypoxia-inducible factors (HIFs) bind hypoxia responsive elements (HREs) within the promoter regions of their target genes [4,5]. HIF target genes include those involved in the regulation of hematopoietic and vascular development, cellular glucose uptake and metabolism, cell proliferation and differentiation, $\mathrm{pH}$ homeostasis, cell death and autophagy [6-14].

HIF heterodimer comprises one of three major oxygen-sensitive HIF- $\alpha$ subunits (HIF- $1 \alpha$, HIF- $2 \alpha$ or HIF-3 $\alpha$ ) and a constitutively expressed $\beta$-subunit (HIF-1 $\beta$, also known as aryl hydrocarbon receptor nuclear translocator, ARNT). These subunits join together to form the HIF-1,
HIF-2 and HIF-3 transcriptional complexes, respectively. The hypoxic response is primarily mediated by the hypoxia-inducible HIF-1 and HIF-2 complexes, which have both overlapping and unique target genes [5]. Their transcriptional activities, protein stabilization, protein-protein interactions, and cellular localization are mainly modulated by post-translational modifications such as hydroxylation, ubiquitination, acetylation, phosphorylation and $S$-nitrosylation $[15,16]$. Recently, we reported that polycomb chromobox 4 (Cbx4, Figure 1A) governs the transcriptional activity of HIF- $1 \alpha$ by enhancing its sumoylation, and hence potentiating angiogenesis of hepatocellular carcinoma (HCC) [17]. Here we review the current understanding of HIF- $1 \alpha$ sumoylation, and its effects on protein stabilization and transcriptional activity of HIF-1, as well as its roles in the pathogenesis of cancer.

*Corresponding author (email: chengq@ shsmu.edu.cn or gqchen@sibs.ac.cn) 

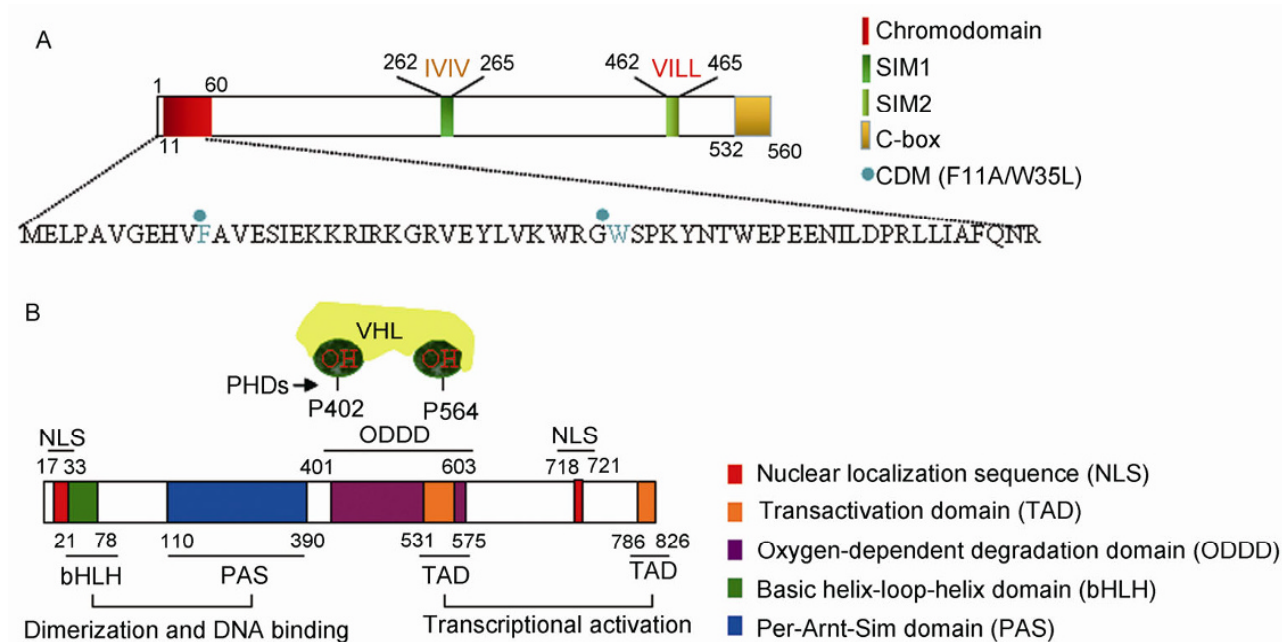

Figure 1 The schematic structure of Cbx4 (A) and HIF-1 $\alpha$ proteins (B).

\section{Ubiquitin-dependent and independent deg- radation of HIF-1 $\alpha$ protein}

The human HIF-1 $\alpha$ subunit contains 826 amino acids with an approximate molecular weight of $120 \mathrm{kD}$ [18]. The schematic structure of HIF- $1 \alpha$ protein is shown in Figure 1B. It carries two nuclear localization sequences that are responsible for translocation of the accumulated HIF- $1 \alpha$ protein to the nucleus under hypoxic conditions [19]. The transcriptional activity of HIF-1 $\alpha$ is determined by two transactivation domains (TADs) respectively in its $\mathrm{N}$-terminal and C-terminal [20-22]. Deletion of amino acids 576-785 of HIF-1 $\alpha$ increases its transcriptional activity [20], suggesting that this region possibly contains an inhibitory domain. HIF-1 $\alpha$ also contains a basic helix-loop-helix (bHLH) domain that mediates its dimerization with HIF-1 $\beta$ subunits, and a Per-Arnt-Sim domain (PAS) to be responsible for DNA binding [21]. Intriguingly, most post-translational modifications occur within the oxygen-dependent degradation domain (ODDD) which plays a crucial role in the hypoxia-dependent stabilization of HIF-1 $\alpha$ [23].

Under normoxic conditions, prolyl hydroxylases 1-3 (PHD1-3) hydroxylate the proline residues at positions 402 and 564 within the ODDD of HIF-1 [24,25]. HIF-1 hydroxylation is essential for the binding of the von Hippel-Lindau (VHL) tumor suppressor protein, one component of a multiple protein ubiquitin-ligase complex VHL/elongin B/ elongin C [26-28]. This E3 ubiquitin ligase complex links a ubiquitin chain to HIF-1 $\alpha$ and directs it to the proteasome complex for proteolytic degradation [29]. As PHDs use oxygen as a cofactor for their hydroxylation activity, these enzymes become inactive under hypoxic conditions, resulting in non-hydroxylation of prolines 402 and 564, and inhibition of VHL binding. Consequently, the HIF-1 $\alpha$ protein is stabilized and translocated into the nucleus [19], where it binds to HREs to regulate expression of its target genes (Figure 2). In addition to VHL, murine double minute 2 [30] and Jab1 [31] have also been reported to affect the ubiquitination and stability of HIF-1 $\alpha$. It should be pointed out that the protein stability and transcriptional activity of HIF-1 can be regulated by several other factors besides hypoxia, such as the accumulation of intermediate metabolites, the loss of tumor-suppressor function and the gain of oncogene function [32].

HIF-1 $\alpha$ protein can be degraded by a mechanism that is independent of VHL, hypoxia and the ubiquitination machinery [33]. SHARP1, a crucial regulator of the invasive and metastatic phenotype in triple-negative breast cancer, was reported to inhibit the aggressiveness of the subtype of cancer through binding to HIF- $1 \alpha$ and HIF- $2 \alpha$. SHARP1 acts as the HIF-presenting factor to the proteasome resulting in the proteasomal degradation of HIF- $1 \alpha$ and HIF-2 $\alpha$ (Figure 2). Remarkably, histone deacetylase (HDAC) inhibitors have also been shown to induce the proteasomal degradation of HIF- $1 \alpha$ in a mechanism that is independent of VHL or the ubiquitin system. The mechanism involves the enhanced interaction of HIF-1 $\alpha$ with heat shock protein (HSP) 70 and is secondary to a disruption of the HSP70/HSP90 axis function that appears to be mediated by the activity of HDAC-6 [34].

\section{Sumoylation and HIF-1 $\alpha$}

The small ubiquitin-related modifiers (SUMOs) share only about $18 \%$ sequence identity with ubiquitin, but SUMOs and ubiquitin are structurally quite similar. Four SUMO paralogues (designated SUMO-1, -2, -3, and -4) have been identified in mammals [35]. Like ubiquitin, SUMOs can be covalently attached to lysine residues within their target proteins via an enzymatic cascade involving a heterodimeric 


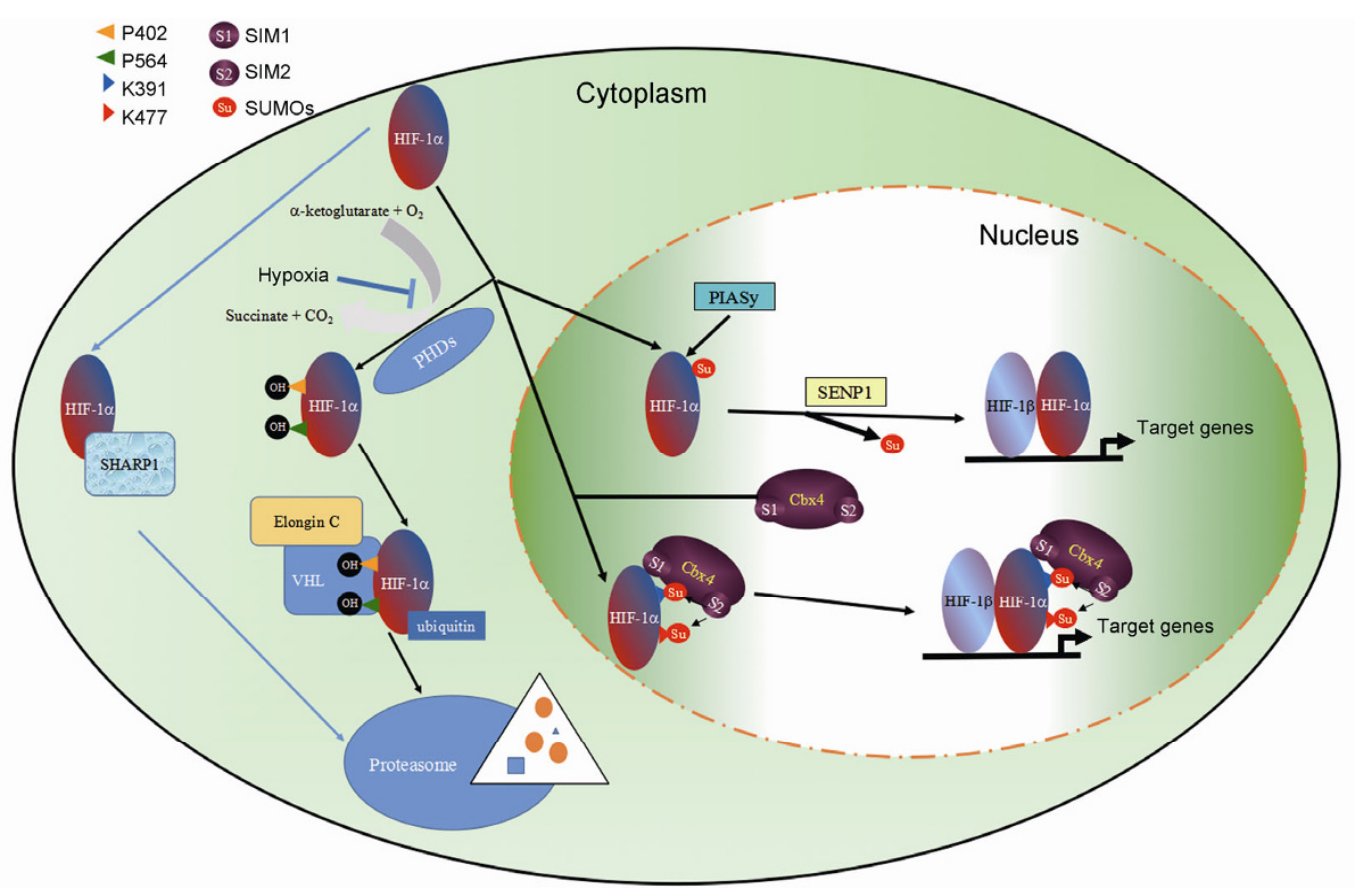

Figure 2 Regulation of the stability and transcriptional activity of HIF-1 $\alpha$ protein by sumoylation.

E1-activating enzyme (SAE1/2), an E2-conjugating enzyme (Ubc9), and a growing number of distinct E3 ligases (Figure 3 ), which can increase the efficiency and specificity of the sumoylation process [36]. The activated SUMOs are transferred from the heterodimeric E1 to Ubc9 through a thioester linkage between diglycine residues at the extreme $\mathrm{C}$ terminus of mature SUMO proteins and the active site cysteine of Ubc9. Subsequently, the SUMO moiety is ligated onto an acceptor lysine residue of a substrate in a process that can be enhanced by a SUMO E3 ligase. However, Ubc9 is sufficient to promote substrate sumoylation, in the absence of ligase, at least in vitro [36,37].

Sumoylation has emerged as an important regulatory posttranslational event in mammals, as evidenced by the embryonic lethality of mouse mutants lacking Ubc9 [38]. Sumoylation modulates a diverse range of biological processes such as gene transcription, DNA replication and repair, chromosome segregation, and the transport of proteins through the nuclear pore $[36,39,40]$. In addition to the covalent attachment of SUMOs to lysine residues in target proteins, some specific motifs mediate non-covalent interactions with SUMOs [41-44]. In general, these motifs comprised a hydrophobic core, which is often flanked by acidic residues. The best-characterized SUMO interaction motifs (SIMs) have the consensus sequence, V/I-X-V/I-V/I or V/I-V/I-X-V/I/L, where $\mathrm{X}$ is any amino acid $[43,44]$. Structural studies have demonstrated that these hydrophobic SIMs bind to the second $\beta$-strand and the first $\alpha$ helix of SUMOs. With increased attention focused on the noncovalent interaction of SUMOs with SIM-containing proteins, it has become clear that there is some flexibility in

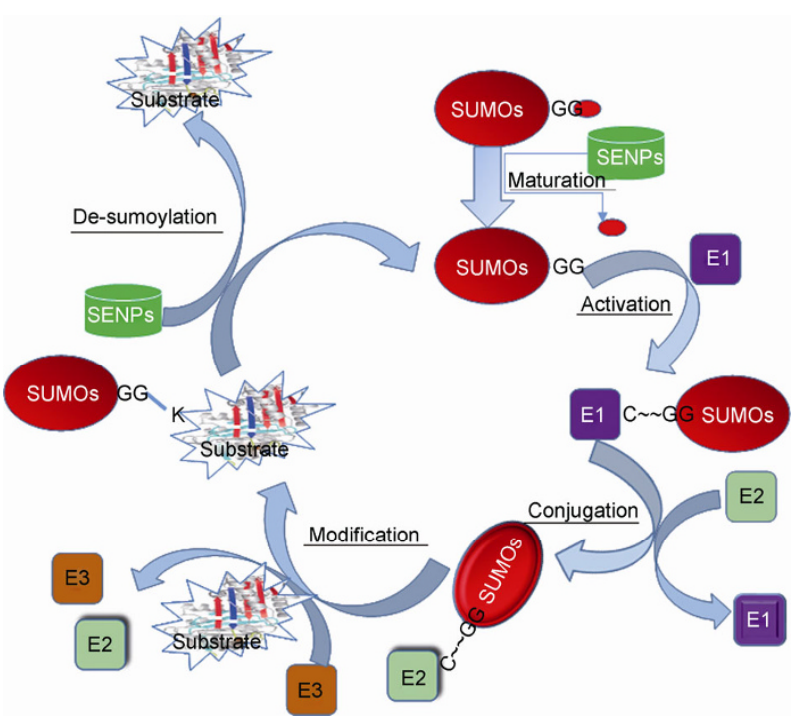

Figure 3 The sequential activation of an enzymatic cascade for protein sumoylation from SUMO maturation by SENPs, SUMO activation by the E1 enzyme, conjugation to the E2 enzyme UBC9, SUMO linkage to the protein substrate by E3 ligase and SUMO deconjugation.

the precise sequence of the hydrophobic core of the SIMs. For example, the corepressor CoREST1 binds to SUMO-2 via a SIM with a five amino acid core in which positions 1 , 3 and 5 are hydrophobic residues [45]. Such results suggest that further variation in consensus SIMs will be found, emphasizing the importance of testing the functionality of potential SIMs.

Previous studies of HIF-1 $\alpha$ sumoylation have produced conflicting results [46-49]. Originally, Bae et al. [46] found 
that ectopic SUMO-1 expression in HEK 293T cells increases the stability of cotransfected HIF- $1 \alpha$, thus enhancing the transcriptional activity of HIF-1 protein in which HIF- $1 \alpha$ is sumoylated at lysines 391 and 477. CarbiaNagashima et al. [48] reported that the RWD-containing sumoylation enhancer (RSUME) is induced by hypoxia and enhances overall SUMO-1, -2, and -3 conjugation. Moreover, RSUME enhances HIF-1 $\alpha$ sumoylation, thus promoting the stabilization and transcriptional activities of HIF-1 during hypoxia.

Berta et al. [47] revealed that HIF- $1 \alpha$ undergoes sumoylation by SUMO-1, -2 and -3 in vitro, in proximity to, and within the ODDD domain, in a process promoted by the SUMO E3 ligase RanBP2/Nup538. However, contrary to the studies mentioned above, they found that in vivo sumoylation does not change HIF-1 $\alpha$ turnover rate and decreases its transcriptional activity. The SUMO E3 ligase PIASy was also reported to enhance hypoxia-induced HIF- $1 \alpha$ sumoylation and to negatively regulate its stability and transactivation [50]. Furthermore, sentrin/SUMOspecific protease 1 (SENP1), a desumoylation enzyme, stabilizes HIF-1 $\alpha$ and enhances its transcriptional activity by removing SUMO. This was proposed to be because sumoylation of HIF-1 $\alpha$ promotes its binding to VHL through a proline hydroxylation-independent mechanism, leading to HIF-1 $\alpha$ ubiquitination and degradation (Figure 2) [49].

\section{Cbx4 and HIF-1 $\alpha$ sumoylation}

Polycomb group $(\mathrm{PcG})$ proteins are major transcriptional repressors that epigenetically modify chromatin. PcGs include structurally diverse and functionally related proteins, many of which interact with each other to form multimeric, chromatin-associated protein complexes called polycomb repressive complexes (PRC), e.g., PRC1 and PRC2 in mammals. These complexes are important for the regulation of many biological processes such as the cell-division cycle, DNA repair, cell differentiation, senescence and death. Cbx proteins, including $\mathrm{Cbx} 2, \mathrm{Cbx} 4, \mathrm{Cbx} 6, \mathrm{Cbx} 7$, and $\mathrm{Cbx} 8$, are the core components of the PRC1 complex. The classification of members of the Cbx family is based on the presence of a single N-terminal chromodomain (Figure 1A), which, in at least some members of the family, can bind to histone proteins via methylated lysine residues [51]. More interestingly, human $\mathrm{Cbx} 4$ (also known as polycomb 2, Pc2) also has SUMO E3 ligase activity [51], for which a limited repertoire of substrates have been identified, including C-terminus binding protein 1 [52], DNA methyltransferase 3a [53], Smad-interacting Protein 1 [54], centrin-2 [55], and homeodomain-interacting protein kinase 2 [56].

Recently, we reported that $\mathrm{Cbx} 4$ directly interacts with, and enhances overall SUMO-1, -2 , and -3 conjugation to
HIF- $1 \alpha$ protein in HCC cells. HIF- $1 \alpha$ can be desumoylated by ectopic SENP1 expression. Under hypoxic conditions, the silencing of $\mathrm{Cbx} 4$ by its specific shRNAs inhibits HIF- $1 \alpha$ sumoylation in HCC cells [17]. Recent analyses have shown that for Cbx4 two functional SIMs (SIM1 and SIM2, Figure 1A) are prerequisites for its SUMO E3 ligase activity [57,58]. For HIF-1 $\alpha$ sumoylation, SIM1 of Cbx4 contributes to its interaction with HIF- $1 \alpha$ protein, and SIM2 is essential for its SUMO E3 ligase activity. Furthermore, we found that $\mathrm{Cbx} 4$ promotes HIF- $1 \alpha$ sumoylation at lysines 391 and 477 within the ODDD of HIF-1 $\alpha$. Intriguingly, HIF-1 $\alpha$ with mutations of these two sumoylation sites still interacts with $\mathrm{Cbx} 4$ with similar binding affinity to that of wild-type HIF- $1 \alpha$, and it can also be recruited to the promoter region of HIF-1 targeted gene vascular endothelial growth factor (VEGF) together with $\mathrm{Cbx} 4$. However, the DNA binding ability and transcriptional activity of mutated HIF- $1 \alpha$ cannot be enhanced by $\mathrm{Cbx} 4$. Therefore, we conclude that $\mathrm{Cbx} 4$ upregulates the transcriptional activity of HIF- $1 \alpha$ through enhancing the sumoylation of HIF- $1 \alpha$ at K391 and K477, as depicted in Figure 2 [17].

\section{HIF-1 $\alpha$ sumoylation and cancer}

As described above, HIF-1 $\alpha$ has been established as a strong promoter of tumor progression by effects on processes including neovascularization, glucose metabolism, energy metabolism, migration, invasion, autophagy and cell death [59]. As sumoylation might regulate the stability and/or transcriptional activity of HIF- $1 \alpha$, the regulators of HIF- $1 \alpha$ sumoylation are presumed to play crucial roles in tumorigenesis. Indeed, PIASy was reported to inhibit the angiogenic activity of endothelial cells, and its expression is inversely correlated with tumor angiogenesis in colon cancer [50]. SENP1 is highly expressed in both precancerous prostate intraepithelial neoplasia lesions and prostate cancer tissues, and its expression correlates with prostate cancer aggressiveness and recurrence [60,61]. With in vitro and in vivo assays, SENP1 is recognized as a promoter of colony formation, migration, invasion, tumor growth and metastasis in nude mice of prostate cancer cell lines [61]. In addition, SENP1 inhibition promotes the apoptosis of Burkitt lymphoma cells [62].

It has been reported that SUMO-1 is highly expressed in HCC cell lines and clinical HCC samples, while the expression level of SUMO-1 in non-neoplastic liver tissues was significantly lower [63]. Analysis of a large cohort of HCC tissues allowed us to report that $\mathrm{Cbx} 4$ is highly expressed in most of these tissues, and that elevated $\mathrm{Cbx} 4$ protein is positively correlated with poor overall survival of HCC patients [54]. Wang et al. [64] also showed that Cbx4 expression was upregulated in multiple HCC cell lines and clinical samples, and that HCC patients with a high level of cyto- 
plasmic $\mathrm{Cbx} 4$ have a shorter overall and recurrence-free survival. Intriguingly, our further investigations demonstrated that $\mathrm{Cbx} 4$ expression is also positively correlated with VEGF expression and microvessel density (MVD) [17]. In line with these clinical observations, overexpression of $\mathrm{Cbx} 4$ but not other members of the Cbx family promotes VEGF expression and in vitro angiogenesis in several HCC cell lines under hypoxia. Conversely, silencing of $\mathrm{Cbx} 4$ by shRNAs dramatically blocks hypoxia-induced VEGF production and in vitro angiogenesis. The Cbx4-CDM mutant (F11A/W35L double-mutation in the chromodomain of $\mathrm{Cbx} 4)$ has lost its polycomb function but still possesses SUMO E3 ligase activity. Ectopic expression of the Cbx4-CDM mutant increases hypoxia-induced VEGF production and the hypoxia-induced tube-forming ability of vascular endothelial cells to a similar degree to wild-type Cbx4. In contrast, no such increases are seen for all three $\Delta \mathrm{Cbx} 4-\mathrm{SIM}$ mutants, which maintain the polycomb function but lose SUMO E3 ligase activity [17]. Conversely, the knockdown of HIF-1 $\alpha$ or HIF-1 $\beta$ with their specific shRNAs almost completely abolishes hypoxia-induced VEGF expression, supporting the essential role of HIF-1 sumoylation in Cbx4-dependent VEGF expression.

In line with these in vitro findings, subcutaneously and orthotopically transplanted tumors originated from HCC cell lines ectopically expressing wild-type $\mathrm{Cbx} 4$ or its $\mathrm{CDM}$ mutant, but not the $\Delta \mathrm{Cbx} 4-\mathrm{SIM} 1 / 2$ mutant, grew much faster compared with vehicle controls. Accordingly, ectopic expression of $\mathrm{Cbx} 4$ or $\mathrm{Cbx} 4-\mathrm{CDM}$, but not $\Delta \mathrm{Cbx} 4-\mathrm{SIM} 1 / 2$, dramatically increases VEGF expression and MVD in the transplanted tumors [17]. Moreover, orthotopically transplanted SMMC-7721 [17] and MHCC97L cells [65] ectopically expressing $\mathrm{Cbx} 4$ and $\mathrm{Cbx} 4-\mathrm{CDM}$ present significantly more lung metastasis nodules than vehicle and $\Delta \mathrm{Cbx} 4-$ SIM1/2-infected tumors. Conversely, the knockdown of endogenous Cbx4 causes SMMC-7721 and MHCC97L cells to produce significantly lower tumor burden than cells transfected with vehicle alone in BALB/c nude mice [17].

\section{Perspectives}

The physiological and pathophysiological roles of HIF-1 have been widely recognized and its post-translational modifications have attracted wide interest. However, HIF-1 $\alpha$ sumoylation appears to be very complicated. Dimova and Kietzmann [15] proposed that the effects of sumoylation on HIF-1 $\alpha$ vary from cell type to cell type. More intriguingly, we have shown that $\mathrm{Cbx} 4$ and PIASy-mediated HIF-1 $\alpha$ sumoylations have different effects on the stability and transcriptional activity of HIF-1 in HCC cell lines. Actually, PIASy has no effect on both K391 and K477-mutated HIF-1 $\alpha$, suggesting that $\mathrm{Cbx} 4$ and PIASy promote HIF-1 $\alpha$ sumoylations at different lysines. Therefore, we propose that different sumoylation patterns produced by specific SUMO E3 ligases might lead to different influences on the stability and transcriptional activity of HIF-1 $\alpha$. However, the sumoylation sites of HIF-1 $\alpha$ by PIASy and other SUMO E3 ligases remain to be identified. Alternatively, different sumoylation patterns produced by different SUMO E3 ligases could possibly affect HIF- $1 \alpha$-interacting proteins, which could contribute to the regulation of the stability and transcriptional activity of HIF-1 $\alpha$ indirectly. Therefore, it remains to be further explored how Cbx4-induced HIF-1 $\alpha$ sumoylation at K391 and K477 increases the DNA binding ability and thus the transcriptional activity of HIF-1.

It has previously been shown that some coactivators and corepressors contribute to the regulation of the transcriptional activity of HIF-1 [66-68]. We presume that sumoylation could affect the interaction of HIF-1 with these known or unknown co-modulators, thus regulating its transcriptional activity. In fact, our preliminary proteomic experiments do indeed reveal different interaction partners for non-sumoylated HIF- $1 \alpha$ and HIF- $1 \alpha$ proteins with Cbx4enhanced sumoylation. Therefore, it would be useful to explore these interaction partners and their roles in the regulation of stability and function of HIF-1 to uncover the mechanism by which sumoylation of HIF-1 $\alpha$ regulates its transcriptional activity. Regardless of the outcome of such investigations, the development of reagents targeting the SUMO E3 ligase activity of $\mathrm{Cbx} 4$, and the interacting sites between $\mathrm{Cbx} 4$ and HIF-1 $\alpha$, could be beneficial for inhibiting the tumor angiogenesis essential for cancer cells to fulfill their need for oxygen and nutrients.

Finally, increasing lines of evidence have shown that hypoxia and HIF-1 contribute to differentiation of acute myeloid leukemia [69-75], consistent with the fact that people living at high altitude appear to have a lower risk of leukemia [76-79]. Our investigations showed that HIF-1-mediated leukemic cell differentiation is independent of the transcriptional activity of HIF-1 [80]. In short, hypoxia-stabilized HIF-1 $\alpha$ interacts with and increases the transcriptional activity of $\mathrm{C} / \mathrm{EBP} \alpha$ and Runt-related protein 1 (Runx1, also named acute myeloid leukemia-1, AML1) [81-83]. Therefore, the question of whether sumoylation of HIF-1 $\alpha$ contributes to leukemogenesis and leukemic cell differentiation deserves further investigation.

The work of our group described in this review was supported by grants from the National Natural Science Foundation of China (91213304, 31101044), the National Basic Research Program of China (NO2009CB918404), Shanghai Science \& Technology Committee (11JC1406800) and Shanghai Committee of Education and Doctoral Innovation Fund Projects from Shanghai Jiao Tong University School of Medicine. 
1 Pouyssegur J, Dayan F, Mazure NM. Hypoxia signalling in cancer and approaches to enforce tumour regression. Nature, 2006, 441: 437-443

2 Floor SL, Dumont JE, Maenhaut C, Raspe E. Hallmarks of cancer: of all cancer cells, all the time? Trends Mol Med, 2012, 18: 509-515

3 Hanahan D, Coussens LM. Accessories to the crime: functions of cells recruited to the tumor microenvironment. Cancer Cell, 2012, 21: 309-322

4 Semenza GL. Hypoxia-inducible factors in physiology and medicine. Cell, 2012, 148: 399-408

5 Koh MY, Powis G. Passing the baton: the HIF switch. Trends Biochem Sci, 2012, 37: 364-372

6 Bellot G, Garcia-Medina R, Gounon P, Chiche J, Roux D, Pouyssegur J, Mazure NM. Hypoxia-induced autophagy is mediated through hypoxia-inducible factor induction of BNIP3 and BNIP31 via their BH3 domains. Mol Cell Biol, 2009, 29: 2570-2581

7 Xin X, Rodrigues M, Umapathi M, Kashiwabuchi F, Ma T, Babapoor-Farrokhran S, Wang S, Hu J, Bhutto I, Welsbie DS, Duh EJ, Handa JT, Eberhart CG, Lutty G, Semenza GL, Montaner S, Sodhi A Hypoxic retinal muller cells promote vascular permeability by HIF-1-dependent up-regulation of angiopoietin-like 4. Proc Natl Acad Sci USA, 2013, 110: E3425-3434

8 Dang EV, Barbi J, Yang HY, Jinasena D, Yu H, Zheng Y, Bordman Z, Fu J, Kim Y, Yen HR, Luo W, Zeller K, Shimoda L, Topalian SL, Semenza GL, Dang CV, Pardoll DM, Pan F. Control of T(H)17/T(reg) balance by hypoxia-inducible factor 1. Cell, 2011, 146: 772-784

9 Fukuda R, Zhang H, Kim JW, Shimoda L, Dang CV, Semenza GL. HIF-1 regulates cytochrome oxidase subunits to optimize efficiency of respiration in hypoxic cells. Cell, 2007, 129: 111-122

10 Sendoel A, Kohler I, Fellmann C, Lowe SW, Hengartner MO. HIF-1 antagonizes p53-mediated apoptosis through a secreted neuronal tyrosinase. Nature, 2010, 465: 577-583

11 Liu W, Shen SM, Zhao XY, Chen GQ. Targeted genes and interacting proteins of hypoxia inducible factor-1. Int J Biochem Mol Biol, 2012, 3: 165-178

12 Zhao XY, Zhao KW, Jiang Y, Zhao M, Chen GQ. Synergistic induction of galectin-1 by CCAAT/enhancer binding protein alpha and hypoxia-inducible factor 1alpha and its role in differentiation of acute myeloid leukemic cells. J Biol Chem, 2011, 286: 36808-36819

13 Zhao XY, Chen TT, Xia L, Guo M, Xu Y, Yue F, Jiang Y, Chen GQ, Zhao KW. Hypoxia inducible factor-1 mediates expression of galectin-1: the potential role in migration/invasion of colorectal cancer cells. Carcinogenesis, 2010, 31: 1367-1375

14 Liao SH, Zhao XY, Han YH, Zhang J, Wang LS, Xia L, Zhao KW, Zheng Y, Guo M, Chen GQ. Proteomics-based identification of two novel direct targets of hypoxia-inducible factor-1 and their potential roles in migration/invasion of cancer cells. Proteomics, 2009, 9: 3901-3912

15 Dimova EY, Kietzmann T. Hypoxia-inducible factors: posttranslational crosstalk of signaling pathways. Methods Mol Biol, 2010, 647: 215-236

16 Lim JH, Lee YM, Chun YS, Chen J, Kim JE, Park JW. Sirtuin 1 modulates cellular responses to hypoxia by deacetylating hypoxia-inducible factor 1alpha. Mol Cell, 2010, 38: 864-878

17 Li J, Xu Y, Long XD, Wang W, Jiao HK, Mei Z, Yin QQ, Ma LN, Zhou AW, Wang LS, Yao M, Xia Q, Chen GQ. Cbx4 governs HIF-1alpha to potentiate angiogenesis of hepatocellular carcinoma by its SUMO E3 ligase activity. Cancer Cell, 2014, 25: 118-131

18 Wang GL, Jiang BH, Rue EA, Semenza GL. Hypoxia-inducible factor 1 is a basic-helix-loop-helix-pas heterodimer regulated by cellular $\mathrm{O}_{2}$ tension. Proc Natl Acad Sci USA, 1995, 92: 5510-5514

19 Kallio PJ, Okamoto K, O'Brien S, Carrero P, Makino Y, Tanaka H, Poellinger L. Signal transduction in hypoxic cells: Inducible nuclear translocation and recruitment of the $\mathrm{CBP} / \mathrm{p} 300$ coactivator by the hypoxia-inducible factor-1alpha. EMBO J, 1998, 17: 6573-6586

20 Jiang BH, Zheng JZ, Leung SW, Roe R, Semenza GL. Transactiva- tion and inhibitory domains of hypoxia-inducible factor 1alpha. Modulation of transcriptional activity by oxygen tension. J Biol Chem, 1997, 272: 19253-19260

21 Pugh CW, O'Rourke JF, Nagao M, Gleadle JM, Ratcliffe PJ. Activation of hypoxia-inducible factor-1; definition of regulatory domains within the alpha subunit. J Biol Chem, 1997, 272: 11205-11214

22 Ema M, Hirota K, Mimura J, Abe H, Yodoi J, Sogawa K, Poellinger L, Fujii-Kuriyama Y. Molecular mechanisms of transcription activation by HLF and HIF1alpha in response to hypoxia: their stabilization and redox signal-induced interaction with CBP/p300. EMBO J, 1999, 18: 1905-1914

23 Huang LE, Gu J, Schau M, Bunn HF. Regulation of hypoxia-inducible factor 1alpha is mediated by an $\mathrm{O}_{2}$-dependent degradation domain via the ubiquitin-proteasome pathway. Proc Natl Acad Sci USA, 1998, 95: 7987-7992

24 Jaakkola P, Mole DR, Tian YM, Wilson MI, Gielbert J, Gaskell SJ, von Kriegsheim A, Hebestreit HF, Mukherji M, Schofield CJ, Maxwell PH, Pugh CW, Ratcliffe PJ. Targeting of HIF-alpha to the von Hippel-Lindau ubiquitylation complex by $\mathrm{O}_{2}$-regulated prolyl hydroxylation. Science, 2001, 292: 468-472

25 Masson N, Willam C, Maxwell PH, Pugh CW, Ratcliffe PJ. Independent function of two destruction domains in hypoxia-inducible factor-alpha chains activated by prolyl hydroxylation. EMBO J, 2001, 20: 5197-5206

26 Maxwell PH, Wiesener MS, Chang GW, Clifford SC, Vaux EC, Cockman ME, Wykoff CC, Pugh CW, Maher ER, Ratcliffe PJ. The tumour suppressor protein VHL targets hypoxia-inducible factors for oxygen-dependent proteolysis. Nature, 1999, 399: 271-275

27 Ohh M, Park CW, Ivan M, Hoffman MA, Kim TY, Huang LE, Pavletich N, Chau V, Kaelin WG. Ubiquitination of hypoxia-inducible factor requires direct binding to the beta-domain of the von Hippel-Lindau protein. Nat Cell Biol, 2000, 2: 423-427

28 Min JH, Yang H, Ivan M, Gertler F, Kaelin WG Jr., Pavletich NP. Structure of an HIF-1alpha -PVHl complex: hydroxyproline recognition in signaling. Science, 2002, 296: 1886-1889

29 Kaelin WG Jr., Ratcliffe PJ. Oxygen sensing by metazoans: the central role of the HIF hydroxylase pathway. Mol Cell, 2008, 30: 393-402

30 Ravi R, Mookerjee B, Bhujwalla ZM, Sutter CH, Artemov D, Zeng Q, Dillehay LE, Madan A, Semenza GL, Bedi A. Regulation of tumor angiogenesis by p53-induced degradation of hypoxia-inducible factor 1alpha. Genes Dev, 2000, 14: 34-44

31 Bae MK, Ahn MY, Jeong JW, Bae MH, Lee YM, Bae SK, Park JW, Kim KR, Kim KW. Jab1 interacts directly with HIF-1alpha and regulates its stability. J Biol Chem, 2002, 277: 9-12

32 Yang H, Xiong Y, Guan K. Metabolic alteration in tumorigenesis. Sci China Life Sci, 2013, 56: 1067-1075

33 Montagner M, Enzo E, Forcato M, Zanconato F, Parenti A, Rampazzo E, Basso G, Leo G, Rosato A, Bicciato S, Cordenonsi M, Piccolo S. SHARP1 suppresses breast cancer metastasis by promoting degradation of hypoxia-inducible factors. Nature, 2012, 487: 380-384

34 Kong X, Lin Z, Liang D, Fath D, Sang N, Caro J. Histone deacetylase inhibitors induce VHL and ubiquitin-independent proteasomal degradation of hypoxia-inducible factor 1alpha. Mol Cell Biol, 2006, 26: 2019-2028

35 Hay RT. Protein modification by SUMO. Trends Biochem Sci, 2001, 26: $332-333$

36 Johnson ES. Protein modification by SUMO. Annu Rev Biochem, 2004, 73: 355-382

37 Hay RT. SUMO: a history of modification. Mol Cell, 2005, 18: 1-12

38 Nacerddine K, Lehembre F, Bhaumik M, Artus J, Cohen-Tannoudji M, Babinet C, Pandolfi PP, Dejean A. The SUMO pathway is essential for nuclear integrity and chromosome segregation in mice. Dev Cell, 2005, 9: 769-779

39 Gill G. Something about SUMO inhibits transcription. Curr Opin Genet Dev, 2005, 15: 536-541 
40 Geiss-Friedlander R, Melchior F. Concepts in sumoylation: a decade on. Nat Rev Mol Cell Biol, 2007, 8: 947-956

41 Hannich JT, Lewis A, Kroetz MB, Li SJ, Heide H, Emili A, Hochstrasser M. Defining the SUMO-modified proteome by multiple approaches in saccharomyces cerevisiae. J Biol Chem, 2005, 280: 4102-4110

42 Minty A, Dumont X, Kaghad M, Caput D. Covalent modification of p73alpha by SUMO-1. Two-hybrid screening with p73 identifies novel SUMO-1-interacting proteins and a SUMO-1 interaction motif. J Biol Chem, 2000, 275: 36316-36323

43 Song J, Durrin LK, Wilkinson TA, Krontiris TG, Chen Y. Identification of a SUMO-binding motif that recognizes sumo-modified proteins. Proc Natl Acad Sci USA, 2004, 101: 14373-14378

44 Song J, Zhang Z, Hu W, Chen Y. Small ubiquitin-like modifier (SUMO) recognition of a SUMO binding motif: a reversal of the bound orientation. J Biol Chem, 2005, 280: 40122-40129

45 Ouyang J, Shi Y, Valin A, Xuan Y, Gill G. Direct binding of CoREST1 to SUMO-2/3 contributes to gene-specific repression by the LSD1/CoREST1/HDAC complex. Mol Cell, 2009, 34: 145-154

46 Bae SH, Jeong JW, Park JA, Kim SH, Bae MK, Choi SJ, Kim KW. Sumoylation increases HIF-1alpha stability and its transcriptional activity. Biochem Biophys Res Commun, 2004, 324: 394-400

47 Berta MA, Mazure N, Hattab M, Pouyssegur J, Brahimi-Horn MC. Sumoylation of hypoxia-inducible factor-1alpha reduces its transcriptional activity. Biochem Biophys Res Commun, 2007, 360: 646-652

48 Carbia-Nagashima A, Gerez J, Perez-Castro C, Paez-Pereda M, Silberstein S, Stalla GK, Holsboer F, Arzt E. Rsume, a small RWD-containing protein, enhances SUMO conjugation and stabilizes HIF-1alpha during hypoxia. Cell, 2007, 131: 309-323

49 Cheng J, Kang X, Zhang S, Yeh ET. SUMO-specific protease 1 is essential for stabilization of HIF1alpha during hypoxia. Cell, 2007, 131: 584-595

50 Kang X, Li J, Zou Y, Yi J, Zhang H, Cao M, Yeh ET, Cheng J. Piasy stimulates HIF1alpha sumoylation and negatively regulates HIF1alpha activity in response to hypoxia. Oncogene, 2010, 29: 5568-5578

51 Wotton D, Merrill JC. Pc2 and SUMOylation. Biochem Soc Trans, 2007, 35: 1401-1404

52 Kagey MH, Melhuish TA, Wotton D. The polycomb protein Pc2 is a SUMO E3. Cell, 2003, 113: 127-137

53 Li B, Zhou J, Liu P, Hu J, Jin H, Shimono Y, Takahashi M, Xu G. Polycomb protein $\mathrm{Cbx} 4$ promotes SUMO modification of de novo DNA methyltransferase Dnmt3a. Biochem J, 2007, 405: 369-378

54 Long J, Zuo D, Park M. Pc2-mediated sumoylation of Smadinteracting protein 1 attenuates transcriptional repression of Ecadherin. J Biol Chem, 2005, 280: 35477-35489

55 Klein UR, Nigg EA. SUMO-dependent regulation of centrin-2. J Cell Sci, 2009, 122: 3312-3321

56 Roscic A, Moller A, Calzado MA, Renner F, Wimmer VC, Gresko E, Ludi KS, Schmitz ML. Phosphorylation-dependent control of Pc2 SUMO E3 ligase activity by its substrate protein HIPK2. Mol Cell, 2006, 24: 77-89

57 Merrill JC, Melhuish TA, Kagey MH, Yang SH, Sharrocks AD, Wotton D. A role for non-covalent SUMO interaction motifs in Pc2/CBX4 E3 activity. PLoS ONE, 2010, 5: e8794

58 Yang SH, Sharrocks AD. The SUMO E3 ligase activity of Pc2 is coordinated through a SUMO interaction motif. Mol Cell Biol, 2010, 30: 2193-2205

59 Semenza GL. Targeting HIF-1 for cancer therapy. Nat Rev Cancer, 2003, 3: 721-732

60 Bawa-Khalfe T, Cheng J, Lin SH, Ittmann MM, Yeh ET. SENP1 induces prostatic intraepithelial neoplasia through multiple mechanisms. J Biol Chem, 2010, 285: 25859-25866

61 Wang Q, Xia N, Li T, Xu Y, Zou Y, Zuo Y, Fan Q, Bawa-Khalfe T, Yeh ET, Cheng J. SUMO-specific protease 1 promotes prostate cancer progression and metastasis. Oncogene, 2013, 32: 2493-2498
62 Huang BB, Gao QM, Liang W, Xiu B, Zhang WJ, Liang AB. Down-regulation of SENP1 expression increases apoptosis of Burkitt lymphoma cells. Asian Pac J Cancer Prev, 2012, 13: 2045-2049

63 Guo WH, Yuan LH, Xiao ZH, Liu D, Zhang JX. Overexpression of SUMO-1 in hepatocellular carcinoma: a latent target for diagnosis and therapy of hepatoma. J Cancer Res Clin Oncol, 2011, 137: 533-541

64 Wang B, Tang J, Liao D, Wang G, Zhang M, Sang Y, Cao J, Wu Y, Zhang R, Li S, Ding W, Zhang G, Kang T. Chromobox homolog 4 is correlated with prognosis and tumor cell growth in hepatocellular carcinoma. Ann Surg Oncol, 2013, 20(Suppl 3): S684-692

65 Mei Z, Jiao HK, Wang W, Li J, Chen GQ, Xu Y. Polycomb chromobox 4 enhances migration and pulmonary metastasis of hepatocellular carcinoma cell line MHHC97L. Sci China Life Sci, 2014, 57: 610-617

66 Luo W, Chang R, Zhong J, Pandey A, Semenza GL. Histone demethylase JMJD2C is a coactivator for hypoxia-inducible factor 1 that is required for breast cancer progression. Proc Natl Acad Sci USA, 2012, 109: E3367-3376

67 Galbraith MD, Allen MA, Bensard CL, Wang X, Schwinn MK, Qin B, Long HW, Daniels DL, Hahn WC, Dowell RD, Espinosa JM. HIF1 $\alpha$ employs CDK8-mediator to stimulate RNAPII elongation in response to hypoxia. Cell, 2013, 153: 1327-1339

68 Kato H, Tamamizu-Kato S, Shibasaki F. Histone deacetylase 7 associates with hypoxia-inducible factor 1alpha and increases transcriptional activity. J Biol Chem, 2004, 279: 41966-41974

69 Jiang Y, Xue ZH, Shen WZ, Du KM, Yan H, Yu Y, Peng ZG, Song MG, Tong JH, Chen Z, Huang Y, Lubbert M, Chen GQ. Desferrioxamine induces leukemic cell differentiation potentially by hypoxia-inducible factor-1 alpha that augments transcriptional activity of CCAAT/enhancer-binding protein-alpha. Leukemia, 2005, 19: 1239-1247

70 Zhang J, Song LP, Huang Y, Zhao Q, Zhao KW, Chen GQ. Accumulation of hypoxia-inducible factor-1 alpha protein and its role in the differentiation of myeloid leukemic cells induced by all-trans retinoic acid. Haematologica, 2008, 93: 1480-1487

71 He M, Wang QY, Yin QQ, Tang J, Lu Y, Zhou CX, Duan CW, Hong DL, Tanaka T, Chen GQ, Zhao Q. HIF-1alpha downregulates miR-17/20a directly targeting p21 and STAT3: a role in myeloid leukemic cell differentiation. Cell Death Differ, 2013, 20: 408-418

72 Nguyen-Khac F, Della Valle V, Lopez RG, Ravet E, Mauchauffe M, Friedman AD, Huang LE, Fichelson S, Ghysdael J, Bernard OA. Functional analyses of the TEL-ARNT fusion protein underscores a role for oxygen tension in hematopoietic cellular differentiation. Oncogene, 2006, 25: 4840-4847

73 Kim JS, Cho EW, Chung HW, Kim IG. Effects of tiron, 4,5-dihydroxy-1,3-benzene disulfonic acid, on human promyelotic hl-60 leukemia cell differentiation and death. Toxicology, 2006, 223: 36-45

74 Huang Y, Du KM, Xue ZH, Yan H, Li D, Liu W, Chen Z, Zhao Q, Tong JH, Zhu YS, Chen GQ. Cobalt chloride and low oxygen tension trigger differentiation of acute myeloid leukemic cells: Possible mediation of hypoxia-inducible factor-1alpha. Leukemia, 2003, 17: 2065-2073

75 Liu W, Guo M, Xu YB, Li D, Zhou ZN, Wu YL, Chen Z, Kogan SC, Chen GQ. Induction of tumor arrest and differentiation with prolonged survival by intermittent hypoxia in a mouse model of acute myeloid leukemia. Blood, 2006, 107: 698-707

76 Eckhoff ND, Shultis JK, Clack RW, Ramer ER. Correlation of leukemia mortality rates with altitude in the United States. Health Phys, 1974, 27: 377-380

77 Losman JA, Looper RE, Koivunen P, Lee S, Schneider RK, McMahon C, Cowley GS, Root DE, Ebert BL, Kaelin WG Jr. (R)-2-hydroxyglutarate is sufficient to promote leukemogenesis and its effects are reversible. Science, 2013, 339: 1621-1625

78 Weinberg CR, Brown KG, Hoel DG. Altitude, radiation, and mortal- 
ity from cancer and heart disease. Radiat Res, 1987, 112: 381-390

79 Losman JA, Kaelin WG Jr. What a difference a hydroxyl makes: mutant IDH, (R)-2-hydroxyglutarate, and cancer. Genes Dev, 2013, 27: $836-852$

80 Song LP, Zhang J, Wu SF, Huang Y, Zhao Q, Cao JP, Wu YL, Wang LS, Chen GQ. Hypoxia-inducible factor-1alpha-induced differentiation of myeloid leukemic cells is its transcriptional activity independent. Oncogene, 2008, 27: 519-527

81 Pabst T, Mueller BU, Harakawa N, Schoch C, Haferlach T, Behre G, Hiddemann W, Zhang DE, Tenen DG. AML1-ETO downregulates the granulocytic differentiation factor C/EBPalpha in $\mathrm{t}(8 ; 21)$ myeloid leukemia. Nat Med, 2001, 7: 444-451

82 Peng ZG, Zhou MY, Huang Y, Qiu JH, Wang LS, Liao SH, Dong S, Chen GQ. Physical and functional interaction of Runt-related protein 1 with hypoxia-inducible factor-1alpha. Oncogene, 2008, 27: 839847

83 Yang L, Jiang Y, Wu SF, Zhou MY, Wu YL, Chen GQ. CCAAT/enhancer-binding protein alpha antagonizes transcriptional activity of hypoxia-inducible factor 1 alpha with direct protein-protein interaction. Carcinogenesis, 2008, 29: 291-298

Open Access This article is distributed under the terms of the Creative Commons Attribution License which permits any use, distribution, and reproduction in any medium, provided the original author(s) and source are credited. 